\title{
Study on chemical mechanical ultra precision process technology of Aluminum Interconnected Line for ULSI
}

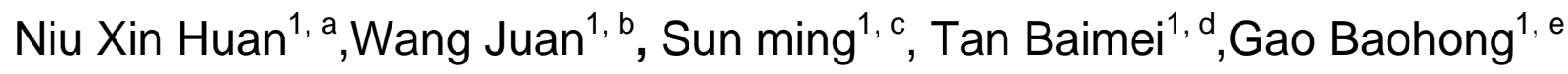 \\ ${ }^{1}$ IInstitute of Microelectronics, Hebei University of Technology, Tianjin, 300130,China

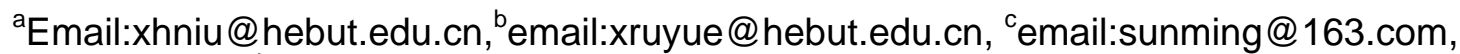 \\ demail:bmtan@hebut.edu.cn, ${ }^{\mathrm{e} e m a i l: x i n g g u o j i a @ 163 . c o m ~}$
}

Keywords: ULSI, Aluminum interconnection line, Chemical mechanical polishing

\begin{abstract}
The chemical mechanical polishing ultra precision process technology mechanism of Aluminum Interconnected Line for ULSI was analyzed according the physical and chemical properties of Aluminum. In order to meet the request of environmental protection and reducing ion staining, the alkaline slurry was adopted. The selection reason of $\mathrm{pH}$ value regulator and surfactant was discussed, and their actions during polishing were analyzed. According to the experimental results and optimal technological parameters, the higher removal rate and lower surface roughness were gotten, which were $390 \mathrm{~nm} / \mathrm{min}$ and $0.47 \mathrm{~nm}$ respectively.
\end{abstract}

\section{Introduction}

Aluminum was used as the important metal interconnection material from the first generation integrated circuit(IC) to ULSI manufacturing for its excellent properties, such as low resistivity, low melting point, good adhesive quality, and so on. Above $0.18 \mu \mathrm{m}$ technology node for silicon process manufacture, Aluminum and Aluminum alloy are still the key interconnection material[1].

For the traditional manufacture process, the method of removal metal Aluminum was reactive ion etching(RIE) method. But for lower than $0.25 \mu \mathrm{m}$ technology node device, RIE was not the profit planarization method, for it could't removal the layer material completely which led to short circuit and lower wafer inner uniformity[2]. For the high precision request, the ultra precision process method of chemical mechanical polishing was adopted by semiconductor industries, which not only provided a promising method to achieve global planarization but also generated new possibilities for the development of innovative semiconductor manufacturing processes. According to the recent research report, lower than $45 \mathrm{~nm}$ technology node for CMOS process, HKMG technique becomes the main stream, and Aluminum is used as gate electrode material for replace metal gate(RMG). The size of Aluminum line will be thinner and thinner, so how to control the removal rate and surface roughness becomes the research emphases of RMG Al-CMP[3-4].

The low hardness and complicated electrochemical behavior of Aluminum would require a more sophisticated control over the mechanical parameters and slurry chemistries in its CMP process[5]. In this study, in order to achieve good planarity and low surface roughness, the alkaline medium, organic base as $\mathrm{pH}$ regulator and $\mathrm{FA} / \mathrm{O}$ surfactant were selected.

\section{Analysis of Aluminum interconnection line CMP mechanism}

Physical and chemical properties of Aluminum. Aluminum is an amphoteric metal, and it is easy to be oxidized in the air to form surface passivation film. Fig1 shows the E-pH diagram of Aluminum in aqueous solution.

From this diagram it can be seen that at the different electric potential and $\mathrm{pH}$ regions the different reaction products were formed. There are three $\mathrm{pH}$ regions that produce three distinct 


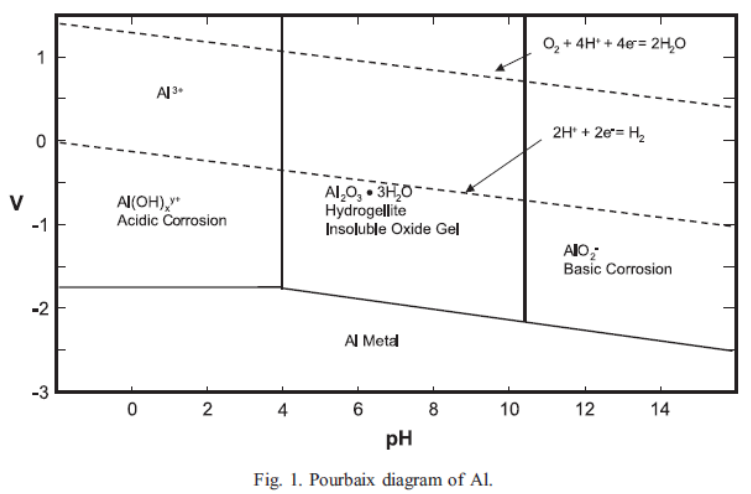

Fig.1 $\mathrm{E}-\mathrm{pH}$ pourbaix diagram of $\mathrm{Al}^{[6]}$

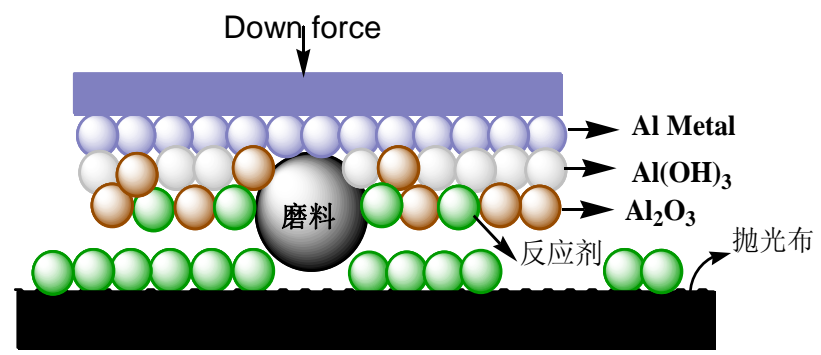

Fig.2 The mechanism model for Al CMP

species. The low $(<4)$ and high $\mathrm{pH}(>8.3)$ regions attack $\mathrm{Al}$ metal, producing soluble $\mathrm{Al}$ ionic species, $\mathrm{Al} 3+$ and $\mathrm{AlO} 2-$, respectively. When operating $\mathrm{CMP}$ within these $\mathrm{pH}$ regions, the slurry must leave the metal surface quick enough to avoid formation of pinholes, corrosion, pitting or any other surface imperfections that would lead to higher surface roughness. Conversely, Al under neutral $\mathrm{pH}$ chemistries forms a protective oxide $\left(\mathrm{Al}_{2} \mathrm{O}_{3} \cdot 3 \mathrm{H}_{2} \mathrm{O}\right)$ that is several times harder than the metal itself and difficult to be removed. So the impossible $\mathrm{pH}$ regions for Al-CMP should be lower than 4 and higher than 8.3 .

Polishing mechanism of $\mathrm{Al}$ interconnection line. According to the $\mathrm{Al}$ characters, for $\mathrm{Al}-\mathrm{CMP}$ the slurry can be acidity, and the $\mathrm{Al}$ metal can be translated into $\mathrm{Al}$ ion to be removed. Also the slurry can be alkalis, then the Al metal can be translated into AlO2- to be removed. But for acid medium, the formed alum ion causes ionic secondary pollution and it takes more difficult for cleaning. So the alkali medium is selected for alkali has passivating action and it can avoid etching equipment, also alkali medium takes important action for abrasive stability and will not cause ionic secondary pollution.

The mechanism model for Al-CMP is shown as Fig2.

Under alkali condition, the chemical reactions as follows:

$$
\begin{aligned}
& 4 \mathrm{Al}+3 \mathrm{H}_{2} \mathrm{O}_{2} \rightarrow 2 \mathrm{Al}_{2} \mathrm{O}_{3} \\
& \mathrm{Al}_{2} \mathrm{O}_{3}+3 \mathrm{H}_{2} \mathrm{O} \Leftrightarrow 2 \mathrm{Al}(\mathrm{OH})_{3} \\
& \mathrm{Al}(\mathrm{OH})_{3}+\mathrm{OH}^{-} \Leftrightarrow \mathrm{AlO}{ }_{2}^{-}+2 \mathrm{H}_{2} \mathrm{O}
\end{aligned}
$$

$$
\begin{aligned}
& \mathrm{Al}_{2} \mathrm{O}_{3}+\mathrm{H}_{2} \mathrm{O} \Leftrightarrow 2 \mathrm{AlO}(\mathrm{OH}) \\
& \mathrm{Al}_{2} \mathrm{O}_{3}+2 \mathrm{OH}^{-} \Leftrightarrow 2 \mathrm{AlO}_{2}^{-}+\mathrm{H}_{2} \mathrm{O}
\end{aligned}
$$

First $\mathrm{Al}$ metal is oxidized by oxidizer to $\mathrm{Al}_{2} \mathrm{O}_{3}$, then $\mathrm{Al}_{2} \mathrm{O}_{3}$, reacts with $\mathrm{H}_{2} \mathrm{O}$ and forms the hydrates of $\alpha$-alumina, and the hardness of such hydrates is lower than $\mathrm{Al}_{2} \mathrm{O}_{3}$. At the same time, a part of substrate material and hydrates react with alkali, and form water soluble $\mathrm{AlO}_{2}^{-} \cdot \mathrm{Al}(\mathrm{OH})_{3}$ is a sort of white gelatinous precipitate, so the reactions must meet the dynamic balance and the reaction products must be remove away quickly, or which can influence the surface quality seriously.

\section{Experimental procedure}

In this study, the polishing equipment is France Alpsitec E460. After polishing and cleaning, the samples surface roughness were measured on Agilent 5600LS. The abrasive size was measured by Mastersizer $3000 \mathrm{HS}$ particle size analyzer.

\section{Results and discussion}

pH regulator. In order to avoid metal ion introduction, macro molecule hydroxylamine is selected as $\mathrm{pH}$ regulator, abbreviated as $\mathrm{R}\left(\mathrm{NH}_{2}\right)_{4}$. So the macro molecule and soluble products can be removed away easily from the sample surface, the reaction for mula as follows:

$$
\begin{gathered}
\mathrm{Al}_{2} \mathrm{O}_{3}+\mathrm{NH}_{2} \mathrm{RNH}_{2}+\mathrm{H}_{2} \mathrm{O} \Rightarrow\left(\mathrm{NH}_{3} \mathrm{RNH}_{3}\right)\left(\mathrm{AlO}_{2}\right)_{2} \\
2 \mathrm{AlO}(\mathrm{OH})+\mathrm{NH}_{2} \mathrm{RNH}_{2} \Rightarrow\left(\mathrm{NH}_{3} \mathrm{RNH}_{3}\right)\left(\mathrm{AlO}_{2}\right)_{2}
\end{gathered}
$$

The action mechanism is shown as Fig3.During the CMP process, there has higher kinetic energy on the hump, so regulator can react with reactant quickly. But at the scoop, the react rate is 
slower for the low kinetic energy. Such good concavo convex selectivity can achieve higher planar effect.

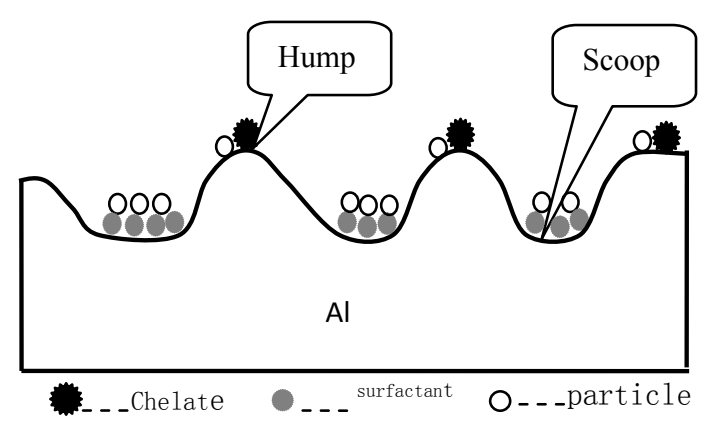

Fig.3 The effect of regent during CMP process

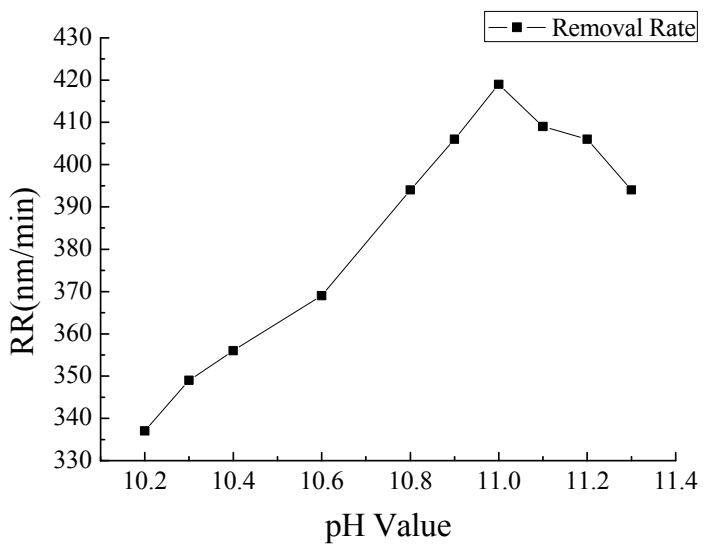

Fig 4 Aluminum RR under different $\mathrm{pH}$ value

Fig4 shows the $\mathrm{Al}$ removal rate changes with different $\mathrm{pH}$. It can be seen that with $\mathrm{pH}$ value rising, the removal rate increase. When the $\mathrm{pH}$ value reaches 11.0 , the removal rate reaches $419 \mathrm{~nm} / \mathrm{min}$ and begins decreasing. With the $\mathrm{pH}$ value increasing, the concentration of $\mathrm{OH}$ - ion also increases, and more soluble meta aluminic acid amine is formed, which can lead to higher removal rate. But when the $\mathrm{AlO}_{2}^{-}$concentration reaches a certain value, the reaction for mula will be backward, and forms a certain quantity $\mathrm{Al}(\mathrm{)H})_{3}$ gelatinous precipitate, which slows down the forming of meta aluminic acid amine and reaction products breaking away from Al surface will be under speed. So the removal rate decreases with $\mathrm{pH}$ value increasing. Otherwise when the concentration is higher, the oxidizer $\mathrm{H}_{2} \mathrm{O}_{2}$ will be decomposed easily and the oxidation properties will be lower. So the $\mathrm{pH}$ value was selected 11.0.

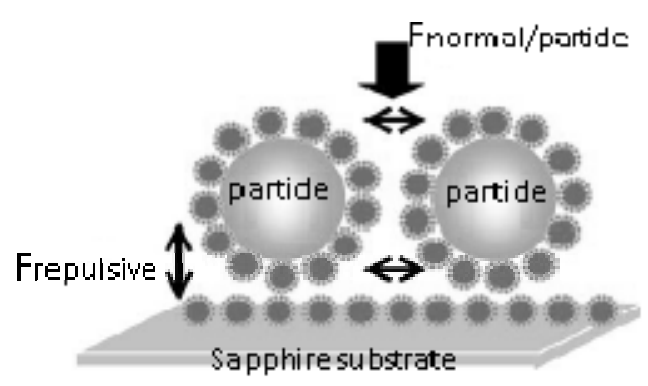

Fig.5 Effect of surfactant on particle-particle and particle-substrate

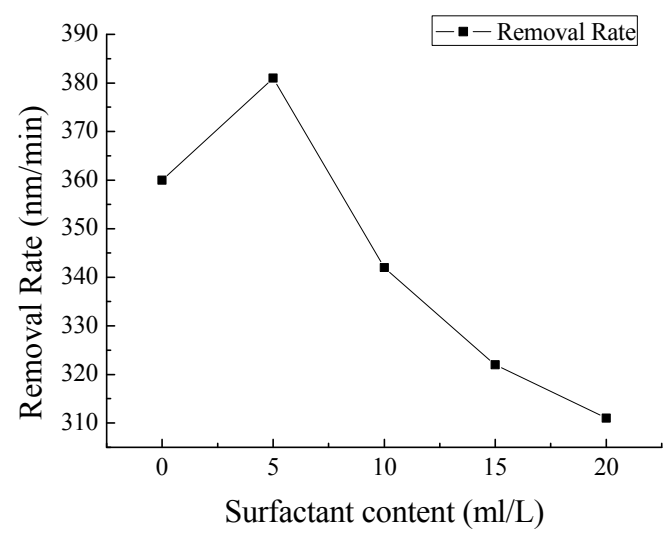

Fig.6 Effect of the surfactant on the removal rate

Surfactant. In this study, FA/O nonionic surfactant is selected, which can ensure slurry stability, enlarge the repulsive force between abrasive particles(Fig5). So the abrasive particles disperse equably and the slurry can keep stable long time. Also it can decrease surface tension and has strong osmosis(Fig3). The removal particles can keep physical adsorption and be taken away from the surface easily.

Fig6 shows the relation of removal rate and surfactant concentration. It can be seen when surfactant concentration is $5 \mathrm{ml} / \mathrm{L}$, the removal rate reaches $386 \mathrm{~nm} / \mathrm{min}$, and with the concentration increasing the removal rate decreases. For more surfactant will weaken the abrasive mechanical action, which leads to the lower removal rate. 


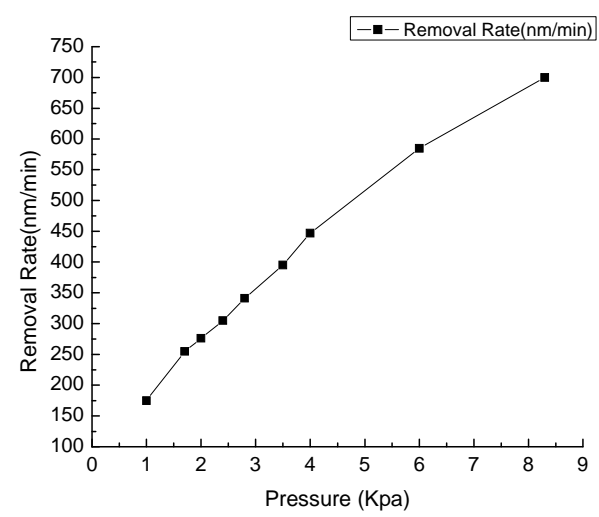

Fig.7 Aluminum RR under different pressure

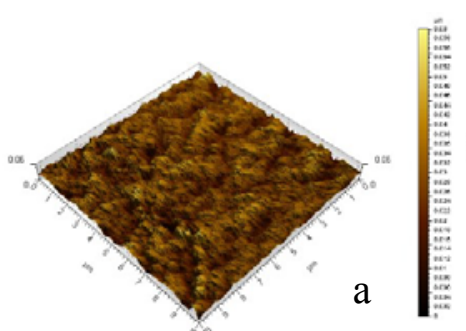

Fig.8AFM images of aluminum surface(a. before CMP,b. after CMP)

Optimal results. Through optimizing the mechanical parameters and slurry chemistries, the removal rate can reach more than $400 \mathrm{~nm} / \mathrm{min}$, and the surface roughness can reach $0.47 \mathrm{~nm}$ with the scope $10 \mu \mathrm{m} \times 10 \mu \mathrm{m}$ (Fig8).

\section{Conclusion}

Under the foundation of analyzing $\mathrm{Al}$ physical chemical properties, the alkali medium was selected for $\mathrm{Al}$ interconnection line CMP and macro molecule hydroxylamine was selected as $\mathrm{pH}$ regulator, which avoided the ion second pollution and can reach the aim of energy conservation and environmental protection. Through optimizing the mechanical parameters and slurry chemistries, the high removal rate and low surface roughness were achieved, and they were higher than $400 \mathrm{~nm} / \mathrm{min}$ and $0.47 \mathrm{~nm}$ respectively.

\section{Acknowledgements}

This work was financially supported by Major national science and technology special projects (2009ZX02308) and Tannin Natural Science Foundation of China (10JCZDJC15500), Specialized Research Fund for the Doctoral Program of Higher Education of China (20111317120005),Fund Project of Hebei Provincial Department of Education (2011128).

\section{References}

[1]JAMES D.P: Silicon VLSI Technology (Electronic Industry Press, Beijing, 2005).

[2]PAUL F, Information on http://www.Solidstatechina.com/Dezzgy.asp?id=66.2011.

[3]D.B.Hsieh,T.C.Tsai,S.F.Huang,et al. Microelectronic Engineerig,Vol.88,(2011), p 583-588

[4]Y.H.Hsieh,H.K.Hsu,T.C.Tsai,et al. Microelectronic Engineering, Vol.92 (2011), p 19-23

[5]WANG Y L,TSENG W T,CHANG S C. Thin Solid Films, Vol.474,( 2005), p 36-43.

[6]LIANG HONG. Tribology International, Vol. 38 (2005), p235-242. 